International Review of Social History 43 (1998), Supplement, pp. I05-124

(C) 1998 Internationaal Instituut voor Sociale Geschiedenis

\title{
The Logic of Qualitative Comparative Analysis
}

\author{
Charles C. Ragin
}

\section{INTRODUCTION}

Social scientists often face a fundamental dilemma when they conduct social research. On the one hand, they may emphasize the complexity of social phenomena - a common strategy in ethnographic, historical and macrosocial research - and offer in-depth case studies sensitive to the specificity of the things they study. On the other hand, they may make broad, homogenizing assumptions about cases, and document generalities - patterns that hold across many instances. Research strategies that focus on complexity are often labeled "qualitative", "case-oriented", "small-N", or "intensive". Those that focus on generality are often labeled "quantitative", "variable-oriented", "large-N", or "extensive". While the contrasts between these two types of social research are substantial, it is easy to exaggerate their differences and to caricature the two approaches, for example, portraying quantitative work on general patterns as scientific but sterile and oppressive, and qualitative research on small Ns as rich and emancipatory but journalistic. It is important to avoid these caricatures because the contrasts between these two general approaches provide important leads both for finding a middle path between them and for resolving basic methodological issues in social science.

Social scientists who study cases in an in-depth manner often see empirical generalizations simply as a means to another end - the interpretive understanding of cases. In this view, a fundamental goal of social science is to interpret significant features of the social world and thereby advance our collective understanding of how existing social arrangements came about and why we live the way we do. The rough general patterns that social scientists may be able to identify simply aid the understanding of specific cases; they are not viewed as predictive. Besides, the task of interpreting and then representing socially significant phenomena (or the task of making selected social phenomena significant by representing them) is a much more immediate and tangible goal. In this view, empirical generalizations and social science theory are important - to the extent that they aid the goal of interpretive understanding.

By contrast, those who study patterns across many cases with an eye toward formulating social scientific generalizations believe that the fundamental goal of social science is to advance general, explanatory theories that address wide expanses of the social terrain. In this view, there is a great deal of order and repetition in social life. Social scientists should uncover general patterns, refine their theories, and use this abstract knowledge to advance the common good. Thus systematic theory is seen as the centerpiece of 
good social science. All social research should be both theoretically driven and relevant.

This bifurcation of social scientists with respect to the issue of generalization is evident in their published work. The examination of almost any social scientific subdiscipline reveals that there is a sharp divide separating those who do small-N, qualitative studies from those who do large-N, quantitative studies. In comparative sociology and comparative politics, for example, a frequency distribution showing the number of studies with different size Ns reveals a clear U-shaped pattern. At the small-N end of the horizontal axis there are many studies, just as there are at the large- $\mathrm{N}$ end of this axis. But in the middle the relative number of studies is very low. There are very few comparativists who conduct studies of 10 or 20 countries, but many who study I or 2 or 75 (i.e. enough to permit the use of conventional quantitative methods).

While easy to explain, there is no simple way to justify this U-shaped pattern. It is true that social scientists value both kinds of knowledge in-depth knowledge of cases and broad statements about patterns that hold across many cases. It is also true that these two forms of knowledge are very different. But in-depth knowledge of cases is often dependent on knowledge of patterns that hold across many cases, and vice versa. Case-oriented researchers, for example, often cite general patterns that they themselves have not documented to explain case-specific phenomena (e.g. citing the "well-known" tendency for peasants to be highly risk averse to explain the failure of an agricultural diversification program). If these general patterns turn out to be without empirical support, then the case-specific argument is suspect (e.g. political corruption, ignored by the researcher, may have stymied the diversification project). Likewise, it is very difficult to explain broad patterns across many cases without reference to case-level processes. ${ }^{1}$ Variable-oriented researchers regularly cite unobserved case-level mechanisms to explain the cross-case patterns they document. If these mechanisms cannot be observed at the case level, then the variable-oriented conclusions are suspect.

Consider also the fact that a deep complementary relationship between case-oriented and variable-oriented research augments their mutual dependence. With variable-oriented techniques, for example, it is very difficult to address questions about actors' motives and subjectivities or to observe event sequences and causal processes. ${ }^{2}$ Case-oriented methods, by contrast, excel in these areas. With case-oriented techniques, however, it is difficult to gain

I. Andrew Abbott, "What Do Cases Do?", in Charles C. Ragin and Howard S. Becker (eds), What Is a Case?' (Cambridge, 1992), pp. 53-82.

2. Dietrich Rueschemeyer and John D. Stephens, "Comparing Historical Sequences: A Powerful Tool for Causal Analysis", Comparative Social Research, XVI (1997), pp. 55-72. 
confidence that inferences are well grounded or that findings are general in any way. These are central strengths of the variable-oriented approach. ${ }^{3}$

The complementarity and mutual dependence of these two types of social research undermines the idea that there can be a convenient division of labor between social scientists who study general patterns and those who interpret significant or important cases. As much as they might want to, the two types of social research simply cannot ignore each other. Perhaps this mutual dependence, combined with an unhealthy measure of mutual suspicion, explains the periodic eruption of "holy wars" in academic journals, departments and other arenas. While it seems unlikely that the boundary separating these two general strategies will ever disappear, it is clear that their tendency toward mutual isolation is unhealthy.

The best way to bridge these two approaches and end the mutual suspicion is to find some middle ground where the concerns of both approaches can be addressed. This middle ground obviously involves compromises on both sides, but it should provide a way to address the practical differences between the two approaches, especially their different approaches to the process of constructing representations of social phenomena from empirical evidence. Finding this middle ground at the same time solves basic methodological issues in social research, for example: must social scientists choose between generality and complexity, between research that is broad but shallow and research that is narrow but deep? Can they have both in the same study - in the same analytic breath?

In the remainder of this paper, I sketch a middle path between complexity and generality. This middle path emphasizes the use of a configurational approach to cases in the analysis of cross-case patterns, and thus retains some of the holism of the case study approach in the analysis of cross-case patterns. ${ }^{4}$ Specifically, I describe a technique called "Qualitative Comparative Analysis" (QCA), originally designed as a formalization of the logic of the comparative case-oriented approach.' In a nutshell, QCA provides analytic tools for conducting holistic comparisons of cases as configurations and for elucidating their patterned similarities and differences. This approach to cross-case research, based on a configurational understanding of social phenomena, is the foundation of what I call "diversity-oriented

3. Stanley Lieberson, "Causal Analysis and Comparative Research: What Can We Learn from Studies Based on a Small Number of Cases?", in Hans-Peter Blossfeld and Gerald Prein (eds), Rational Choice Theory and Large-Scale Data Analysis (Westview, 1998), pp. 129-145.

4. The rationale for this approach is presented in Charles Ragin, The Comparative Method: Moving Beyond Qualitative and Quantitative Strategies (Berkeley, 1987), pp. 121-123, 164-171.

5. Kriss Drass and Charles Ragin, Qualitative Comparative Analysis (Evanston, 1992). QCA is a DOS program distributed by the Institute for Policy Research, Northwestern University. For the full address see the Annotated Bibliography. 
research", which is distinct from case-oriented and variable-oriented research. $^{6}$

Most of the discussion is devoted to describing the application of QCA to dichotomous social data on the memberships of cases in categories and sets. In contrast to statistical methodology, which is based on linear algebra, QCA is based on Boolean algebra, the algebra of logic and sets. QCA treats social scientific categories as sets and views cases in terms of their multiple memberships. In Boolean algebra a case is either "in" or "out" of a set; that is, memberships in sets are "crisp"? Each case is viewed as a member of multiple sets, and membership combinations are compared and contrasted to identify decisive patterns of similarity and difference, which, in turn, provide the basis for constructing causal arguments. With QCA it is possible to view cases as configurations, examine causal complexity (defined as patterns of multiple conjunctural causation - where no single cause may be either necessary or sufficient), and identify types of cases based on the different patterns of causal conditions they exhibit. Thus social scientists can free themselves from some of the restrictive, homogenizing assumptions of variable-oriented social science without giving up the possibility of formulating statements about broad, cross-case patterns.

\section{WORKING WITH CASES AS CONFIGURATIONS}

In QCA, cases are examined in terms of their multiple memberships in sets, viewed as configurations. This interest in how different aspects or features combine in each case is consistent with an emphasis on understanding aspects of cases in the context of the wholes they form. For example, having many small- to medium-sized political parties ("fractionalization") signifies different things about a country's political stability, depending on the nature of its electoral system, its social diversity, the age of its political institutions, and so on. Another example: having many debts can signal different things about a person's financial situation, depending on his or her other attributes - age, income, employment status, assets, and so on. By looking at combinations of aspects, it is possible to get a sense of a case as a whole, especially how its different aspects fit together. This emphasis on how characteristics combine contrasts sharply with the tendency of the variableoriented approach to view aspects of cases as analytically independent features.

In every social scientific investigation, the selection of cases and attributes to study is dependent on the substantive and theoretical interests of the researcher and his or her intended audiences. Sometimes a research literature

6. I contrast diversity-oriented research with case-oriented and variable-oriented research in my forthcoming book, Fuzzy-Set Social Science (Chicago, 1999).

7. In ibid., I show how to work with grades of memberships in sets, using fuzzy algebra. 
is especially well developed, and the selection of cases and attributes is relatively unproblematic. In other situations, however, the researcher can formulate a worthwhile selection of attributes only through in-depth analysis of cases. Sometimes it is necessary to constitute relevant cases and their key aspects through a systematic dialogue of ideas and evidence. Researchers progressively refine their understanding of relevant cases and their key aspects as they sharpen the concepts appropriate for studying them. ${ }^{8}$

Often the selection of aspects is shaped by the nature of the outcome to be investigated and the researcher's understanding of the causal conditions relevant to this outcome. The selection of causal conditions is usually quite broad because the concern is to identify not only the factors that seem connected to the outcome as proximate causes, but also the conditions that provide the contexts for the operation of these factors. A fractionalized party system, for example, could be a proximate cause of political breakdown in some situations; in others, it might be irrelevant and could even contribute to long-term political stability. Thus it is important to consider the contexts and conditions that enable and disable causal connections. This concern for how context structures causal connections is one of the key features of the configurational approach.

Once a set of relevant aspects has been identified, the researcher constructs a table listing the different logically possible combinations of attributes ("configurations") along with the cases that conform to each configuration. This table can be seen as a "property space"; each location within a property space, in turn, can be seen, potentially at least, as a different kind or type of case. 9 In QCA, attributes are represented with presence/ absence dichotomies, with $O$ indicating absence (the case is not in the set in question), and I indicating presence (the case is in the set in question). Multichotomies (e.g. race/ethnicity at the individual level) are represented with sets of dichotomies, which can be arranged in a variery of ways, depending on the interests of the investigator.

By examining the cases that conform to each configuration, represented as a row of the table, it is possible for the investigator to evaluate attributes he has identified. The researcher asks for each configuration: do these cases go together? Are they comparable instances, in the context of this investigation? Thus the configurational understanding of cases problematizes the comparability of cases at the level of the configuration, not simply at the more global level of the population.

Consider, for example, Table I, which shows different configurations of conditions relevant to ethnic political mobilization among territorially-based

8. Charles Ragin, "Turning the Tables: How Case-Oriented Research Challenges VariableOriented Research", Comparative Social Research, XVI (1997), pp. 27-42.

9. Paul F. Lazarsfeld, "Some Remarks on the Typological Procedures in Social Research", Zeitschrift fiur Sozialforschung, VI (1937), PP. I19-139. 
linguistic minorities in Western Europe. Four attributes define the property space: (I) whether the minority is large or small, (2) whether the minority has a weak or strong linguistic base, (3) whether the minority region is richer or poorer than the core region of the host country, and (4) whether the minority region is growing or declining. ${ }^{10}$ There are sixteen logically possible combinations ("configurations") of these four presence/absence dichotomies, and thus sixteen "kinds" of cases. For notational convenience in the discussion that follows, the presence of an attribute is denoted by the name of the attribute; the absence of the attribute (negation) is denoted with the " " symbol preceding the attribute name. Thus, large indicates that the linguistic minority is large in size, while large indicates that it is small; fluent indicates good linguistic ability; $\sim$ fuent indicates poor linguistic ability; wealthy indicates that the minority region is wealthier than the core region; wealthy indicates that it is poorer than the core region; growing indicates that the region is growing; - growing indicates that it is not growing.

Table I also shows the cases conforming to each logically possible combination of these four dichotomies. By evaluating the comparability of the cases conforming to each configuration, the researcher can make a preliminary assessment of the adequacy of the aspects selected for investigation. For example, the first configuration $\left(\sim\right.$ large $e^{*} \sim$ fuent $*^{*} \sim$ wealthy* $\sim$ growing asterisks are used to indicate combinations of characteristics) brings together Lapps in Finland, Lapps in Sweden, Lapps in Norway, Torne Valley Finns in Sweden, Albanians in Italy and Greeks in Italy. Viewing these six cases together, the researcher asks whether or nor it is reasonable to group these as similar cases in a study of the political mobilization of territorially-based linguistic minorities in Western Europe. If not, then additional attributes should be added to the list of relevant causal conditions, or perhaps the researcher should substitute different attributes for some of the existing attributes. For example, the investigator may believe that the four minorities in Scandinavia differ in some causally decisive way from the two minorities in Italy. If so, the causal condition that distinguishes these two groups should be added to the table. The cases conforming to each location in the property space should be evaluated in this manner.

When researchers view their evidence in terms of logically possible combinations of conditions and the cases conforming to each configuration, as in Table I, they also evaluate the cases in each row to see if they display the same outcome, or at least roughly comparable outcomes. For example, a researcher might ask: are the six cases in the first row similar with respect to the ethnic political mobilization they exhibit? Each row is examined in this manner, so that the researcher can gain some confidence that a viable

Io. Erik Allardt, Implications of the Ethnic Revival in Modern, Industrialized Society (Helsinki, 1979), pp. 52-65; Ragin, Comparative Method, pp. I33-149. 
Table I. Territorially-based linguistic minorities in Western Europe

\begin{tabular}{|c|c|c|c|c|c|}
\hline Row & Size & Language & Wealth & Growth & Instances \\
\hline 1 & 〜 large & ｆluent & $\sim$ wealthy & $\sim$ growing & $\begin{array}{l}\text { Lapps, Finland } \\
\text { Lapps, Sweden } \\
\text { Lapps, Norway } \\
\text { Finns, Sweden } \\
\text { Albanians, Italy } \\
\text { Greeks, Italy }\end{array}$ \\
\hline 2 & $\sim$ large & $\sim$ fluent & $\sim$ wealthy & growing & $\begin{array}{l}\text { N. Frisians, Germany } \\
\text { Danes, Germany } \\
\text { Basques, France }\end{array}$ \\
\hline 3 & $\sim$ large & $\sim$ fluent & wealthy & $\sim$ growing & Ladins, Italy \\
\hline 4 & 〜arge & 〜 fluent & wealthy & growing & none \\
\hline 5 & $\sim$ large & fluent & 〜wealthy & $\sim$ growing & $\begin{array}{l}\text { Magyars, Austria } \\
\text { Croats, Austria } \\
\text { Slovenes, Austria } \\
\text { Greenlanders, } \\
\text { Denmark }\end{array}$ \\
\hline 6 & ～large & fluent & 〜 wealthy & growing & none \\
\hline $7^{*}$ & 〜 large & fiuent & wealthy & $\sim$ growing & Aalanders, Finland \\
\hline $8^{*}$ & ～large & fluent & wealthy & growing & $\begin{array}{l}\text { Slovenes, Italy } \\
\text { Valdotians, Italy }\end{array}$ \\
\hline 9 & large & $\sim$ fluent & $\sim$ wealthy & $\sim$ growing & $\begin{array}{l}\text { Sards, Italy } \\
\text { Galicians, Spain }\end{array}$ \\
\hline $10^{*}$ & large & $\sim$ fluent & $\sim$ wealthy & growing & $\begin{array}{l}\text { W. Frisians, Neth. } \\
\text { Catalans, France } \\
\text { Occitans, France } \\
\text { Welsh, Great Britain } \\
\text { Bretons, France } \\
\text { Corsicans, France }\end{array}$ \\
\hline 11 & large & $\sim$ fluent & wealthy & 〜 growing & none \\
\hline $12^{*}$ & large & $\sim$ fluent & wealthy & growing & $\begin{array}{l}\text { Friulians, Italy } \\
\text { Occitans, Italy } \\
\text { Basques, Spain } \\
\text { Catalans, Spain }\end{array}$ \\
\hline 13 & large & fluent & 〜 wealthy & ～growing & Flemings, France \\
\hline $14^{*}$ & large & fluent & 〜 wealthy & growing & Walloons, Belgium \\
\hline $15^{*}$ & large & fluent & wealthy & 〜 growing & $\begin{array}{l}\text { Swedes, Finland } \\
\text { S. Tyroleans, Italy }\end{array}$ \\
\hline $16^{*}$ & large & fluent & wealthy & growing & $\begin{array}{l}\text { Alsatians, France } \\
\text { Germans, Belgium } \\
\text { Flemings, Belgium }\end{array}$ \\
\hline
\end{tabular}

Notes: The " $\sim$ " symbol preceding an attribute name indicates negation. The "*» symbol indicates rows with strong evidence of ethnic political mobilization. Size: whether the minority is large or small. Language: whether the minority has a strong or weak linguistic ability. Wealth: whether the minority region is richer or poorer than the core region of the country. Growth: whether the minority region is growing or declining. 
specification of causal conditions has been realized. Obviously, if the cases in a row display widely divergent outcomes or if they are evenly split between contrasting outcomes, the researcher will examine these cases closely and reformulate his or her specification of causal conditions accordingly. This evaluation of cases with respect to outcomes is separate from the first evaluation, just described, where the researcher asks simply whether or not the cases grouped within each combination of attributes belong together as comparable cases, regardless of their outcomes.

When making assessments of outcomes, it is unrealistic to expect that all the cases in each row will be perfectly consistent with respect to the outcome in question. It is very difficult to capture all causally relevant conditions in broad cross-case analyses. Furthermore, mistakes can be made when assigning cases to sets or when evaluating the evidence with respect to the outcome in question. As an illustration of the general problem, consider the twelfth row of Table I. The Friulian and Occitan minorities of Italy occupy this row, along with the Basques and Catalan minorities of Spain. But the two minorities in Spain are more politically active than the two in Italy, and the Basque minority is more active that the Catalan. This information could be used to identify a fifth causal condition, perhaps specifying a condition relevant to class divisions within linguistic minorities. The researcher might even want to reformulate the property space altogether, with a completely new set of conditions. Alternatively, the researcher might decide simply that there is enough evidence of ethnic political activity across the four cases in this row to justify treating them all as instances of ethnic political mobilization. In other words, the researcher might conclude that the discordance is not so great as to motivate any change in the specification of conditions.

The larger point is that the examination of outcomes is a central part of constructing a property space and generating configurations, especially when it comes to the selection of causally relevant aspects of cases. The researcher conducts an elaborate dialogue of ideas and evidence that leads to a progressive refinement of his or her understanding of relevant cases and to a more nuanced elaboration of the ideas guiding the research. Again, perfect consistency in outcomes for the cases with the same combination of causal conditions is rare. As I show subsequently in this paper, it is possible to use probabilistic criteria when evaluating the links between causal conditions and outcomes. This tactic partially ameliorates the problem of contrary evidence and thus allows for some discordance in outcomes within configurations.

It is important to understand that in QCA the fundamental unit of analysis is the configuration, along with the cases conforming to each configuration. Thus Table I should not be viewed as a presentation of four presence/absence dichotomies, but rather as a specification of sixteen qualitatively distinct conditions - that is, sixteen kinds of cases. The principle of 
holism mandates allowance for the possibility that a single difference between two cases may signal a difference in kind. This thinking provides the conceptual basis for constructing and evaluating evidence in terms of logically possible combinations of causes (i.e. as configurations). Thus the table should be viewed as a property space with sixteen separate locations. Each of the sixteen configurations constitutes, potentially at least, a qualitatively distinct constellation. If 5 dichotomies had been used, there would have been 32 configurations $\left(2^{5}=32\right) ; 6$ dichotomies would yield 64 configurations and so on. Using dichotomies, the number of logically possible combinations is equal to $2^{k}$, where $\mathrm{k}$ is the number of attributes.

The four dichotomies presented in Table I can be viewed not only as sixteen configurations (logically possible combinations of attributes), but also as eighty logically possible groupings. The sixteen configurations presented in Table I provide the elemental or foundational groupings. Additional groupings can be formed by merging configurations that share one or more attributes. For example, the last two rows of Table I, linguistic minorities that are large ${ }^{*}$ fuent $t^{*}$ wealthy* $\sim$ growing (the penultimate row) and

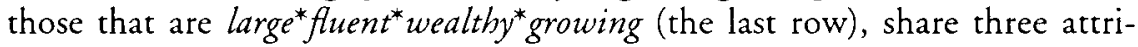
butes and thus can be merged to form a larger grouping, namely minorities that are large $e^{*}$ fuent $t^{*}$ wealthy. In set terminology, the larger set is formed from the union of its component sets. Still larger groupings can be formed from the union of more rows, as long as the rows that are grouped contain at least one attribute in common. For example, the first eight rows display $\sim$ large. Merging these eight rows, yields the set of cases that have $\sim$ large in common - that is, all the smaller linguistic minorities.

Just as it is possible to calculate the logically possible number of combinations $\left(2^{k}\right)$, it is possible to calculate the number of logically possible groupings, including the original sixteen configurations as elemental groupings. The formula is $3^{k}-1$, where $\mathrm{k}$ again is the number of dichotomies. Table 2 shows the logically possible groupings of the four dichotomies presented in Table I. Using the formula just described, there are eighty possible groupings: sixteen elemental groupings involving combinations of four attributes (the original sixteen configurations presented in Table I); thirty-two groupings using combinations of three attributes; twenty-four groupings using two attributes, and eight groupings using one attribute.

These larger groupings are important because they are relevant to any conclusions about cross-case patterns the researcher may wish to construct from the evidence in Table I. For example, the researcher might examine all minorities that are wealthy and growing (wealthy* growing) to see if they have similar levels or forms of ethnic political mobilization. The eighty groupings listed in Table 2 provide the basis for formulating any statement that can be made regarding cross-case patterns. As I show next, the examination of these different groupings is central to the assessment of causal 


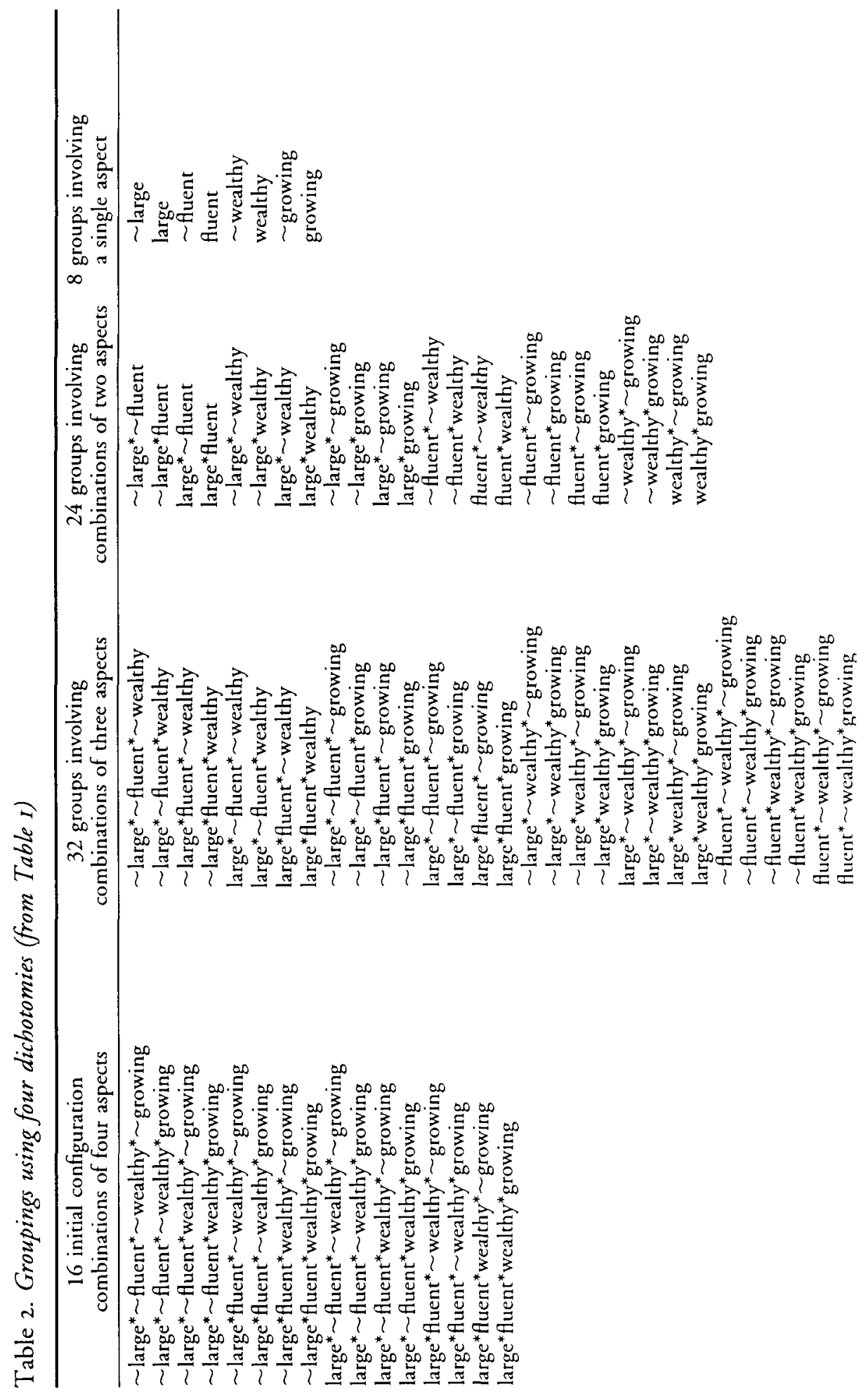


complexity, especially the evaluation of the sufficiency of different combinations of causal conditions.

\section{ANALYZING CAUSAL COMPLEXITY}

Usually, social research begins with the goal of explaining some outcome. For example, a researcher might ask why some territorially-based linguistic minorities participate in politics on an ethnic basis while others do not. Table I, for example, shows that linguistic minorities in rows 7,8 , I0, I2, I4, I5 and 16 offer strong evidence of ethnic political mobilizarion, while those in the other rows offer weak or no evidence of such mobilization. How should the researcher describe the key differences between these two sets of minorities? In other words, what combinations of causal conditions are linked to ethnic political mobilization?

In diversity-oriented research, investigators assume maximum causal complexity. This concern for causal complexity is best implemented by allowing for the possibility that no single causal condition may be either necessary or sufficient for the outcome in question. When no single causal condition is either necessary or sufficient, researchers anticipate finding that different combinations of causal conditions are sufficient for the outcome. This emphasis on causal complexity does not preclude the possibility of finding either a necessary cause or a cause that by itself is sufficient for an outcome. If researchers find that the different combinations of conditions sufficient for an outcome have one or more conditions in common, then the shared cause(s) may be considered necessary, though not sufficient, for the outcome. Researchers also may examine single causes to see if any is sufficient for the outcome.

To assess the sufficiency of a cause or causal combination, the researcher examines the cases conforming to the cause or combination and evaluates whether or not they display the outcome in question. For example, the evidence presented for row ro of Table I (cases conforming to the combination large $e^{*} \sim$ fuent $t^{*} \sim$ wealthy growing $^{*}$ indicates that this causal combination may be sufficient for ethnic political mobilization because all six cases with this combination display ethnic political mobilization. Of course, the researcher must establish standards for evaluating sufficiency. Is six positive cases and no negative cases enough to establish the sufficiency of a causal combination? What about two positive cases and no negative cases, or only one positive case? In each investigation, the investigator must justify the method used to assess sufficiency, based on the nature of the evidence, previous research, the state of relevant theoretical and substantive knowledge, the intended audience for the research, and so on.

The assessment of sufficiency can take either of two general forms. It can be strict, with no allowance for discordant outcomes among the cases conforming to a causal combination, or it can be probabilistic, using 
benchmark proportions. In The Comparative Method and in most applications of the techniques I presented in that work the assessment of the sufficiency of causal combinations is strict: in order to be considered sufficient for an outcome, all the cases conforming to a particular causal combination must display the outcome in question. "When the number of relevant cases is small, as in most comparative research, this method is the only one available; probabilistic assessments of sufficiency require larger numbers. ${ }^{12}$ Because the example developed here, ethnic political mobilization among linguistic minorities, involves a moderate number of cases (36), I present both assessments, strict and probabilistic.

The core of the probabilistic approach to the assessment of the sufficiency of causal combinations is to test the significance of the difference between the observed proportion of positive instances and a benchmark proportion specified by the investigator. The benchmark proportion can be linked to linguistic qualifiers, such as "almost always sufficient" (.80) and "sufficient more often than not" (.50). When the number of cases conforming to a causal combination is modest, say 20 or fewer, researchers should use an exact probability test; otherwise, the $\mathrm{z}$ test for the difference between two proportions will suffice. ${ }^{13}$ To conduct either test, the researcher must set a benchmark proportion and a significance level for making the assessment. For example, a researcher might argue that if the proportion of cases displaying the outcome in question is significantly greater than .65 , with a significance level of .05 (using a one-tailed test), then the causal combination in question is "usually sufficient" for the outcome.

This sufficiency test is applied not only to the original sixteen configurations listed in Table 1 , but also to the remaining 64 groupings listed in columns 2 through 4 of Table 2 . In essence, by applying the test to each of the eighty groupings in Table 2 , the researcher examines all logically possible causal arguments that can be constructed from the four presence/absence dichotomies. In each of the eighty tests of sufficiency, the observed proportion of cases displaying ethnic political mobilization is contrasted with the benchmark proportion (.65) to see if the observed proportion is significantly greater than the benchmark. Eight of the eighty groupings pass the sufficiency test.

II. An early list of applications of QCA is published in Charles Ragin, "Introduction to Qualitative Comparative Analysis", in Thomas Janoski and Alexander Hicks (eds), The Comparative Political Economy of the Welfare State (Cambridge, 1994), pp. 313-317. A more up-to-date list is available from the author upon request.

12. For example, using very generous probabilistic criteria and a relatively weak sufficiency benchmark, an investigator still must have four positive instances and no negative instances for a specific combination of conditions to be judged "sufficient more often than not": see Ragin, Fuzzy-Set Social Science.

I3. William Hays, Statistics (New York, 198I), pp. 2II-2I4. The $z$ test of the statistical significance of the difference between an observed proportion and a benchmark proportion is, in effect, a large- $\mathrm{N}$ approximation of the exact test of the same difference: see ibid., pp. $552-553$. 
None of the sixteen elemental groupings (the configurations from Table I) passes the sufficiency test. For a proportion of 1.0 to be significantly greater than .65 , with a one-tailed significance level of .05, a grouping needs at least 7 cases. Because none of the sixteen configurations has this many cases ( 6 cases is the maximum for these combinations), none passes the sufficiency test. For 6 positive cases and no negative cases to pass a sufficiency test, either the benchmark must be lowered (e.g. to "sufficient more often than not" or .50), or the significance level must be raised (e.g. to .Io significance). Close examination of the eight groupings that pass the sufficiency test reveals that all have very high proportions: seven are I.O; the eighth is .92. Thus, even though the benchmark proportion is relatively modest ("usually sufficient" or .65), only very high proportions with seven or more cases actually pass the test. This result follows from the use of a relatively stringent significance level for evidence of this type.

The eight groupings that pass the sufficiency test are:

I. large* $\sim$ fuent growing $^{*}$

2. large* $\sim$ wealthy* growing

3. large* wealthy* growing

4. large* wealthy

5. large* growing

6. fuent wealthy

7. wealthy* growing

8. wealthy

While it is possible to use the minimization algorithms presented in my book to simplify these eight groupings into a simple logical equation for ethnic mobilization, it is not necessary to do so in this example because the pattern is straightforward. ${ }^{14}$ A logically minimal equation can be derived using the subset rule. Some groupings are subsets of other groupings and thus are redundant. For example, linguistic minorities that are large* wealthy* growing $(\# 3)$ are a subset of minorities that are large* wealthy $(\# 4)$, which in turn are a subset of minorities that are wealthy (\#8). Thus, groupings \#3 and $\# 4$ are contained within grouping $\# 8$ and thus can be eliminated. Altogether, four groupings (\#3, \#4, \#6 and \#7) are subsets of $\# 8$, and three are subsets of \#5 (\#1, \#2 and \#3). These redundant groupings can be dropped. Eliminating these groupings yields the following simplified statement of the causal conditions sufficient for ethnic political mobilization. (As noted previously, in logical statements addition indicates logical or - alternatives; asterisks indicate logical and - the combination of aspects.)

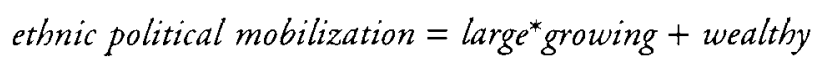

I4. Ragin, Comparative Method, pp. 85-102. 
Using a probabilistic approach to the assessment of causal sufficiency thus produces a relatively parsimonious statement of the conditions for ethnic political mobilization: linguistic minorities that are either wealthy or combine large size and growth are the ones that mobilize. Because these two terms do not contain a common condition, the results show that there is no necessary condition for ethnic political mobilization. However, being wealthy, relative to the core region of the host country, is sufficient, by itself, for such mobilization. Using this logical statement as a prediction equation yields only one incorrect assignment: Ladins of Italy are a false positive. According to the equation they should offer strong evidence of ethnic political mobilization, but using the criteria applied to all linguistic minorities, they do not. In fact, this outlying case is very complex. Ladins in Italy are a territorial minority within a territorial minority - South Tyroleans, a highly mobilized minority. While every ethnic situation is unique, some clearly are more complex than others. More than likely, the researcher would treat this case as an exception to the general patterns specified in the equation and check to see if features specific to this case were of any general relevance to other cases.

Just as the probabilistic approach to the assessment of sufficiency entails specification of benchmarks and significance levels, the alternative, "strict" approach requires a qualitative evaluation of the strength of the evidence. As already noted, if a causal combination includes any negative cases of the outcome, it fails the strict test of sufficiency. Additionally, the investigator may establish a frequency threshold for the number of positive instances. If a causal combination has one positive instance of the outcome and no negative instances, does the evidence support the claim that the causal combination in question is sufficient for the outcome? Is two positive instances enough? How many does it take? Again, the researcher must justify the method used to evaluate sufficiency in each investigation. In some studies, especially small- $\mathrm{N}$ comparative studies of large-scale macrosocial processes and events, a claim of sufficiency may be based on a single positive instance. In other studies, more positive instances may be required.

In order to enhance the potential for contrast with the probabilistic approach, with its implicit frequency threshold - in this example - of seven positive cases when there are no negative cases, the illustration of the strict approach that follows uses a relatively low frequency threshold: if a grouping has no negative instances of the outcome and two or more positive instances of the outcome, it is judged sufficient for ethnic political mobilization. Applying these criteria to the eighty groupings listed in Table 2 yields the following twenty-three that pass the sufficiency test:

I $\sim$ large fluent $^{*}$ wealthy* growing

2. large $^{*} \sim$ fluent $^{*} \sim$ wealthy ${ }^{*}$ growing

3. large $^{*} \sim$ fluent $^{*}$ wealthy* growing $^{*}$ 
4. large $^{*}$ fluent wealthy $^{*} \sim$ growing

5. large* fluent ${ }^{*}$ wealthy ${ }^{*}$ growing

6. - large*fuent*wealthy

7. large* $\sim$ fuent*wealthy

8. large*fuent ${ }^{*}$ wealthy

9. - large fuent $^{*}$ growing

I0. large*$^{*} \sim$ fluent ${ }^{*}$ growing

i1. large fluent $^{*}$ growing

12. - large* wealthy* growing

13. large $^{*} \sim$ wealthy* growing

14. large* wealthy* $\sim$ growing

15. large* wealthy* growing

16. finent* wealthy* growing

17. fluent wealthy* $\sim$ growing

18. fluent $t^{*}$ wealthy ${ }^{*}$ growing

19. large* wealthy

20. large growing $^{2}$

21. fluent*wealthy

22. Auent growing

23. wealthy* growing

The subset rule described previously can be applied to this list to simplify these twenty-three causal combinations into a single logical statement. Alternatively, the minimization algorithms described in The Comparative Method and implemented in the computer program QCA may be used; the results are the same. Applying either technique results in the following logical statement describing the causal combinations linked to ethnic political mobilization:

\section{ethnic political mobilization $=$ large* growing $^{+}$fuent ${ }^{*}$ wealthy}

In short, the results are very similar, though not identical, to those obtained using the probabilistic approach. Translated to prose, the equation states that territorially-based linguistic minorities that combine either large size and growth or a strong linguistic base and greater relative wealth are the ones that exhibit substantial ethnic political mobilization. In this equation, no single condition is either necessary or sufficient because both terms are combinations formed from different causal conditions.

While not as parsimonious as the results using the probabilistic approach, it is easy to see that the two equations differ precisely because the strict test does not allow false positives. Thus, Ladins of Italy are not included in the equation that results from the application of the strict test. They are excluded because of their weaker linguistic ability, compared with the positive cases of mobilization.

It is not productive at this point to ask "Which equation is correct?" 
because correctness is not intrinsic to analytic techniques. Analytic techniques offer social scientists different ways of constructing representations of social phenomena from evidence. ${ }^{15}$ The two equations are nothing more than alternate representations of the evidence on ethnic political mobilization using different rules. In social research, different analytic approaches almost always result in different representations. Which approach is "best" depends on the criteria applied. For example, if the criterion is "no false positives", then the strict approach is best. If the criteria are "makes abundant allowance for imperfect evidence" and "provides greater parsimony", then the probabilistic approach is best. Generally, when the number of cases is small, the first criterion may be more important; when the number is large, the second criteria may be more important.

Ultimately, the question of correctness can be addressed only through case-level analysis. For example, the investigator might take a close look at the positive instances of ethnic political mobilization where greater relative wealth seems important as a causal factor and examine whether or not linguistic ability also seems important in these cases. Additionally, the researcher could ask whether weaker linguistic ability seems to be the main factor impeding the development of strong ethnic political mobilization among Ladins in Italy. More generally, as I stress repeatedly in The Comparative Method and subsequent work, representations of this type, where large amounts of evidence are reduced to broad patterns summarized in an equation (or using some other shorthand), must be evaluated in every instance in terms of their utility for understanding specific cases. Broad representations are best viewed as maps or guides to help a researcher through difficult terrain. They cannot show many details, only the most important. As Charles Tilly would argue, representations of this type "discipline our thinking about [...] complex phenomena in preparation for genuine explanatory efforts" at the case level. ${ }^{16}$

Finally, it is also possible to use summary equations, like the equation for ethnic political mobilization, to differentiate types of cases. Essentially, a summary equation shows, in a logically shorthand manner, the different combinations of conditions linked to some outcome. These different combinations provide a basis for differentiating alternate paths to a given outcome, and cases can be classified according to the paths they travel. For illustration, consider again the results of the strict analysis:

$$
\text { ethnic political mobilization }=\text { large } \text { growing }^{*} \text { fluent }{ }^{*} \text { wealthy }
$$

In essence, the equation states that there are two sets of conditions linked to ethnic political mobilization: large size combined with growth, and

I5. Charles Ragin, Constructing Social Research (Thousand Oaks, 1994), pp. 5-30.

16. Charles Tilly, "Means and Ends of Comparison in Macrosociology", Comparative Social Research, XVI (1997), p. 54. 
Table 3. Conformity of cases to causal combinations

\begin{tabular}{|c|c|c|}
\hline $\begin{array}{l}\text { Minorities that are } \\
\text { large } \text { growing }^{*}\end{array}$ & $\begin{array}{l}\text { Minorities that are } \\
\text { fuent wealthy }\end{array}$ & $\begin{array}{l}\text { Minorities that } \\
\text { conform to both }\end{array}$ \\
\hline $\begin{array}{l}\text { W. Frisians, Netherlands } \\
\text { Catalans, France } \\
\text { Occitans, France } \\
\text { Welsh, Great Britain } \\
\text { Bretons, France } \\
\text { Corsicans, France } \\
\text { Friulians, Italy } \\
\text { Occitans, Italy } \\
\text { Basques, Spain } \\
\text { Catalans, Spain } \\
\text { Walloons, Belgium }\end{array}$ & $\begin{array}{l}\text { Aalanders, Finland } \\
\text { Slovenes, Italy } \\
\text { Valdotians, Italy } \\
\text { Swedes, Finland } \\
\text { S. Tyroleans, Italy }\end{array}$ & $\begin{array}{l}\text { Alsatians, France } \\
\text { Germans, Belgium } \\
\text { Flemings, Belgium }\end{array}$ \\
\hline
\end{tabular}

linguistic strength combined with relative wealth. Table 3 shows the different linguistic minorities conforming to each combination of conditions. Note that three minorities conform to both combinations, as shown in the third column. This pattern of results indicates that both interpretive frames (shown in the first two columns) can be applied to these cases.

While far beyond the scope of this paper, a researcher might find important differences between the nature of the ethnic political mobilization present in these different sets of cases. In fact, an important way to reinforce the results would be to examine the cases to see if differences in the character or course of ethnic mobilization can be traced to differences in relevant causal conditions. In the end, the researcher might be able to differentiate types of ethnic political mobilization and assign cases to types (including mixed types) based on these results. Thus the results provide a basis for reconstituting cases as broad types.

\section{SUMMARY: USING QCA}

There are three distinct phases to the application of QCA to cross-case evidence: (I) selecting cases and constructing the property space that defines kinds of cases (configurations), (2) testing the sufficiency of causal conditions, and (3) evaluating and interpreting the results. As already noted, the summary equations that result from the application of QCA should be viewed as part of the larger dialogue of ideas and evidence. ${ }^{17}$ The real test of any representation of evidence is how well it helps the researcher and his or her audiences understand specific cases or sets of cases. Broad representations of cross-case patterns provide maps that guide and facilitate in-depth investigation; they are not substitutes for this type of investigation. Thus 
QCA has an implicit fourth phase involving the application of the results to specific cases, but this phase is not part of QCA proper.

In many respects the first phase of QCA is the most difficult. The dimensions of the property space (i.e. relevant aspects of cases) must be clarified and refined to see if the resulting scheme sorts cases into kinds that make sense. At the same time, the researcher must study the cases initially chosen for investigation and evaluate whether or not the set as a whole has integrity. Dropping or adding cases may help the researcher refine the property space while at the same time increase the comparability of the cases in the study. Simultaneously, the researcher also examines cases conforming to each configuration defined by the property space with respect to the outcome under investigation, with an eye toward their concordance. If cases differ too greatly on the outcome, then either the property space must be reformulated, the population must be reconstituted, or both.

Once the researcher successfully stabilizes the relevant cases and the property space that sorts them into kinds, then the assessment of causal sufficiency can proceed. In this phase, the key issue is the definition of sufficiency: how should the test be structured? The answer to this question is shaped in large part by the nature of the evidence and the criteria that are most important to the investigator. Still, in most analyses, it is probably best to work with several definitions of sufficiency, and conduct tests favoring competing criteria. Once these tests are complete, algorithms implemented in the program QCA can be used to analyze and simplify the patterns. ${ }^{18}$

More generally, QCA offers comparative analysts a middle path between complexity and generality. With QCA it is possible to allow for causal complexity and case specificity while examining general patterns. The considerable intellectual effort that goes into the construction of a useful property space forces investigators to establish a great deal of empirical intimacy with their cases. Likewise, the procedures used to simplify evidence represented with the resulting property spaces avoid homogenizing assumptions - for example, the idea that a cause must act the same way in all cases - and thus maintain the configurational complexity of individual cases. Finally, the results of QCA provide a basis for interpreting cases, reconstructing them as types, and evaluating their different trajectories. In the end, the results of any application of QCA must be judged relative to their value as interpretive aids in the analysis of specific cases. These results also provide limited generalizations about patterns holding across empirically circumscribed sets of cases.

I8. This introduction to the logic of QCA does not cover two important issues: (I) how to treat logically possible combinations of causes for which there are no empirical instances and (2) how to use theory to evaluate and enrich the results of any logical minimization. These two issues are addressed in ibid., pp. I03-I13, I42-147. 


\section{ANNOTATED BIBLIOGRAPHY}

Abell, Peter, "Foundations for a Qualitative Comparative Method", International Review of Social History, 34, I (1989), pp. 103-109.

This long essay on The Comparative Method (Ragin, 1987) offers a good introduction to the use of Boolean algebra in comparative analysis and suggests some directions for extending the approach.

Amenta, Edwin, Bruce G. Carruthers and Yvonne Zylan, "A Hero for the Aged? The Townsend Movement, the Political Mediation Model, and U.S. Old-Age Policy, 1934-1950", American Journal of Sociology, 98, 2 (1992), pp. 308-339.

This examination of US social policy uses state-level data to test basic arguments about the Townsend movement. The qualitative comparative analysis reinforces conclusions drawn from historical and statistical analyses and shows the different paths to four movement outcomes at the state level: polity membership, concessions, co-optation and collapse.

Berg-Schlosser, Dirk and Gisèle De Meur, "Conditions of Democracy in Inter-War Europe: A Boolean Test of Major Hypotheses", Comparative Politics, 26, 3 (1994), pp. 253-280.

This sophisticated examination of a variety of theoretical arguments presents a wide array of Boolean analyses using qualitative data on conditions conducive to democracy. The authors construct and then simplify truth tables for each major theoretical perspective.

Drass, Kriss A. and Charles C. Ragin, Qualitative Comparative Analysis, Version 3 (Evanston, IL, 1992).

QCA is a software package for Boolean analysis of social data. It is a DOS program distributed on a single diskette along with a brief manual. Available from: Publications Department, Institute for Policy Research, 2040 Sheridan Road, Evanston, IL 60208, USA. The charge is $\$ 25.00$ to cover duplication, postage and handling. Purchasers are welcome to make copies of the program and the documentation to share with other users, as long as they do not charge a fee.

Hicks, Alexander, Joya Misra and Nah Tg Tang, "The Programmatic Emergence of the Social Security State", American Sociological Review, 60, 3 (1995), pp. 329-350.

Focusing on the advanced industrial societies after World War I, this nuanced examination of welfare state consolidation highlights the importance of working-class mobilization. The QCA results in this paper demonstrate the importance of theory in the treatment of logically possible combinations of causes that lack empirical instances.

Lieberson, Stanley and Eleanor O. Bell, "Children's First Names: An Empirical Study of Social Taste", American Journal of Sociology, 98, 3 (I992), pp. 5II-554. 
This paper features a truth table approach to the interpretation of complex data patterns without taking advantage of the formal methods of data reduction. The paper illustrates a concern for configurations and the use of truth tables (property spaces) to represent and analyze complexity. Markoff, John, "A Comparative Method: Reflections on Charles Ragin's Innovations in Comparative Analysis", Historical Methods, 23, 4 (I990), pp. I77-I8I.

Another long essay on The Comparative Method, this discussion addresses the advances afforded by the Boolean approach and sketches its limitations. The primary limitation that Markoff addresses is the fact that the Boolean approach is a method of data analysis that requires a good prior grasp of relevant substantive and historical knowledge.

Ragin, Charles C., The Comparative Method: Moving Beyond Qualitative and Quantitative Strategies (Berkeley, 1987).

The sharp contrast between case-oriented and variable-oriented research strategies provides a backdrop for a systematic, in-depth presentation of Boolean methods of data analysis. A cornerstone of the discussion is the problem of multiple conjunctural causation and the difficulty of assessing this type of causation with linear, statistical models.

Ragin, Charles C., Issues and Alternatives in Comparative Social Research (Leiden, I991).

A collection of essays on comparative methodology. The volume includes two applications of QCA: Larry J. Griffin, Christopher Botsko, AnaMaria Wahl and Larry W. Isaac, "Theoretical Generality, Case Particularity: Qualitative Comparative Analysis of Trade Union Growth and Decline" and Timothy P. Wickham-Crowley, "A Qualitative Comparative Approach to Latin American Revolutions".

Ragin, Charles C., "Introduction to Qualitative Comparative Analysis", in Thomas Janoski and Alexander Hicks (eds), The Comparative Political Economy of the Welfare State (Cambridge, 1994), pp. 299-319.

This paper offers a brief overview of the analytic procedures central to QCA and presents a bibliography of pre-1993 applications.

Ragin, Charles C., "Using Qualitative Comparative Analysis to Study Configurations", in Udo Kelle (ed.), Computer-Aided Qualitative Data Analysis (London, 1995), pp. 177-189.

Two problems structure this discussion of QCA: limited diversity and contradictions. Limited diversity refers to the fact that it is rare that investigators are able to identify empirical instances of all the logically possible combinations of causal factors that are relevant to the property spaces they construct. Contradictions occur when cases with the same combination of causal conditions display discordant outcomes and the investigator is unable, for whatever reason, to resolve these contradictions. 